\title{
Neither Physics nor Chemistry: A History of Quantum Chemistry
}

\section{Citation}

Aspuru-Guzik, Alán. 2012. Neither physics nor chemistry: A history of quantum chemistry. Physics Today 65(8): 52-54.

\section{Published Version}

doi:10.1063/PT.3.1683

\section{Permanent link}

http://nrs.harvard.edu/urn-3:HUL.InstRepos:10288448

\section{Terms of Use}

This article was downloaded from Harvard University's DASH repository, and is made available under the terms and conditions applicable to Other Posted Material, as set forth at http:// nrs.harvard.edu/urn-3:HUL.InstRepos:dash.current.terms-of-use\#LAA

\section{Share Your Story}

The Harvard community has made this article openly available.

Please share how this access benefits you. Submit a story.

\section{Accessibility}




\section{Neither Physics nor Chemistry: A History of Quantum Chemistry}

Alán Aspuru-Guzik

Citation: Phys. Today 65(8), 52 (2012); doi: 10.1063/PT.3.1683

View online: http://dx.doi.org/10.1063/PT.3.1683

View Table of Contents: http://www.physicstoday.org/resource/1/PHTOAD/v65/i8

Published by the American Institute of Physics.

\section{Additional resources for Physics Today}

Homepage: http://www.physicstoday.org/

Information: http://www.physicstoday.org/about_us

Daily Edition: http://www.physicstoday.org/daily_edition

\section{ADVERTISEMENT}

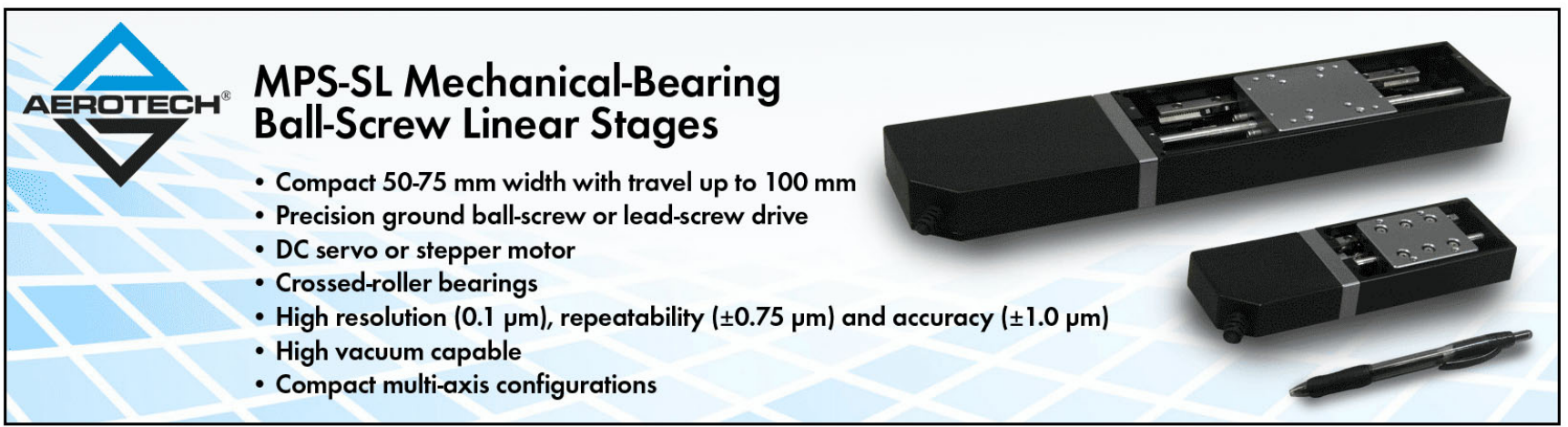


Peliti's Statistical Mechanics in a Nutshell-originally published in Italian (Bollati Boringhieri, 2003) - is a fantastic reference for those who know the subject, teach it, or need a quick technical reminder, especially on the topic of phase transitions, which are consistently featured in modern-day discussions and one that Walecka's book omits. Browsing Peliti's book reminded me of such texts as Kerson Huang's Statistical Mechanics (2nd edition, Wiley, 1987); David Chandler's Introduction to Modern Statistical Mechanics (Oxford University Press, 1987); and Mehran Kardar's Statistical Physics of Particles and Statistical Physics of Fields (both published by Cambridge University Press, 2007).

Of the books under review, Statistical Mechanics in a Nutshell provides the more general overview, with topics such as the renormalization group method. It includes a good mix of fundamental thermodynamics, phase behavior, and other key subjects. Even so, I do not see it as a standalone book for introductory students, even if they are energetic and serious; they will need an expert teacher or practitioner to make the ideas become more vivid in the classroom.

Kimani A. Stancil

Howard University Washington, DC

\section{Introduction to Experimental Biophysics}

\section{Biological Methods for Physical Scientists}

\section{Jay Nadeau \\ CRC Press, Boca Raton, FL, 2012. \\ $\$ 89.95$ (641 pp.). \\ ISBN 978-1-4398-2953-0}

Each year a number of physicists leave various disciplines to become biophysicists. Those converted physicists are challenged to learn various life-science laboratory techniques applicable to molecular biology, microbiology, biochemistry, and cell biology, among other subfields. They also must become familiar with the spectroscopic, microscopic, and other important physical techniques that are now staples of many biological physics labs.

Those challenges highlight the need for effective laboratory manuals, proto- cols, guides, and other instructional material. Jay Nadeau's Introduction to Experimental Biophysics: Biological Methods for Physical Scientists is an ambitious text aimed at educating new graduate students about the important and most common techniques used in a modern biological physics laboratory; it could also serve nicely as a reference manual for advanced graduate students of new or underused protocols. Whereas most existing texts of its kind are aimed at educating biologists or biochemists, Nadeau's is aimed at young biophysicists and more seasoned researchers transferring to the field.

Introduction to Experimental Biophysics includes chapters that cover basic concepts behind commonly used biological techniques - for example, transfection, protein purification, and protein crystallography. Other, more physically flavored chapters discuss the concepts behind microscopy, surface chemistry, inorganic nanoparticles, and quantum dots. Each chapter contains protocols and the conceptual reasoning behind them, which is often useful to physicists performing biological experiments for the first time. Specific gems of the book include an overview in chapter 1 of the physical principles common in biological systems; a detailed experimental overview in chapter 5 of $x$-ray protein crystallization and a useful troubleshooting section to help novices; and a number of extremely useful discussions in chapter 10 on surface modification and functionalization. Surface preparation is particularly important in biophysics: If done incorrectly, it can ruin an otherwise beautiful experiment. The end of each chapter includes extensive references, information about equipment suppliers, helpful websites and software, and additional experimental protocols.

Despite its more than 600 pages, the book is still lacking in some aspects. Perhaps that's not surprising, given its broad scope and ambitious nature. First, most chapters give few details about advanced techniques. For instance, in chapter 6, which covers light microscopy, only one paragraph discusses total internal reflection fluorescence microscopy. Nowhere does the book mention optical or magnetic tweezers, which are used in force spectroscopy and are prevalent in modern biological physics laboratories. Further, various microscopies are discussed in multiple chapters, with electron microscopy (only scanning EM and not transmission EM) addressed in chapter 8 and atomic force microscopy presented in chapter 10 .

The book does not mention techniques that use phospholipids, has insufficient information on chromatographic techniques, and lacks a discussion of the usefulness of centrifugation. New entrants to the field would benefit from learning about the best strategies to extract data-a skill that is not always obvious to beginners-and from knowing the limits of the various techniques, as was done in the troubleshooting section of chapter 5 on protein crystallization and in the example experiments for flow cytometry in chapter 7.

Overall, the many outstanding qualities of Introduction to Experimental Biophysics should make it an essential part of the biophysicist's collection. For new students, it is best partnered with the following texts. At the Bench: A Laboratory Navigator (Cold Spring Harbor Laboratory Press, 2005), by Kathy Barker, contains useful information about the social forces that shape the establishment of laboratories and how to cope with working in the lab on a daily basis. And Principles and Techniques of Biochemistry and Molecular Biology (7th edition, Cambridge University Press, 2010), edited by Keith Wilson and John Walker, provides useful basic information, including a table of units and standard formulas needed to analyze biochemical data.

Introduction to Experimental Biophysics assumes readers are already acclimated to the lab and can figure out for themselves how to analyze the data, if only they could get the data using the right biological experimental techniques. This book is likely to become increasingly useful with future editions and iterations, but in its current state, other sources-most likely collaborating biologists - will be required to fill in the gaps.

\section{Jennifer L. Ross \\ University of Massachusetts Amherst}

\section{Neither Physics nor Chemistry}

\section{A History of Quantum Chemistry}

Kostas Gavroglu and Ana Simões MIT Press, Cambridge, MA, 2012. $\$ 40.00$ (351 pp.).

ISBN 978-0-262-01618-6

The way new areas of science are birthed is similar to the way continental masses are formed: by the contact and 
interaction of previously existing structures, which are subsequently modified

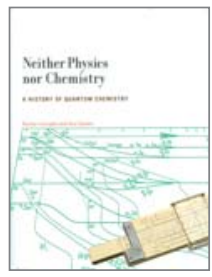
so that they never are what they were before. And just as interactions between continental masses lead to tectonic events such as earthquakes and volcanic activity, the gestation of a new scientific field is usually not smooth.

Quantum chemistry was born in a rocky, volcanic fashion, and the history of its formation has not been covered extensively until now. In Neither Physics nor Chemistry: A History of Quantum Chemistry, historians of science Kostas Gavroglu and Ana Simões trace the development of a field that came about through interactions among physics, chemistry, applied mathematics, and what we now call computer science. An illuminating and well-researched book, Neither Physics nor Chemistry covers the half-century expansion period of the 1920 s to the 1970 s, from the era of Walter Heitler and Fritz London through the tensions between the chemists and physicists, between the New World and the Old, and even among the actors in the field with differing political affilia- tions. The book is full of interesting anecdotes, quotes, and foundational ideas conceived by those players.

Neither Physics nor Chemistry parallels Image and Logic: A Material Culture of Microphysics (University of Chicago Press, 1997; reviewed by W. K. H. Panofsky in PHYSICS TODAY, December 1997, page 65). In Image and Logic, author Peter Galison paints a similar multidisciplinary picture of the birth of particle physics. In particular, in a chapter on computer simulation, Galison describes the conceptual "trading zone" between the physicists and computer engineers that, starting in the 1940s, led to the use of the first computers, such as the MANIAC at Los Alamos, to carry out Monte Carlo simulations. The book narrates the visionary work, from around the same time, of chemist Samuel Boys, who used the EDSAC computer in the UK to carry out early quantum chemistry calculations.

The biographies of the heroes of quantum chemistry are less known than those of the founders of quantum mechanics or of the creators of the atomic bomb. Many people know about Wolfgang Pauli or Werner Heisenberg, but fewer know about Hans Hellman or Robert Mulliken. Neither Physics nor
Chemistry addresses that discrepancy. Moreover, it contains plenty of material about the critical discussions that are still relevant to how chemists work. If one wants to dig to the roots of why organic chemists still think in a "local" valence bonding picture, yet many theoretical chemists are rooted in molecular orbital theory, this book provides the historical context.

Almost a hundred years have passed since the beginnings of quantum chemistry, and both of the parent fields, quantum physics and chemistry, have changed a lot. One thrust of current quantum mechanics is quantum technology: Every day we witness advances in the development of novel devices that could be used for quantum information processing. Meanwhile, theorists are developing new ideas based on quantum information, and experimental physical chemists are using light to probe atoms and molecules at very short times and very high energies. The interaction between 21st-century physics and chemistry might lead either to a renewal of quantum chemistry or to a new field that harvests the current developments from physics and chemistry. Perhaps one might call it quantum information chemistry; that

Experts

\section{One-Off or Production Quantities} High or Ultra-High Vacuum Single Wall or Water-Cooled 85,000 Feet of Manufacturing ISO 9001-2008 Certified In-House Electropolish CMM \& RGA Inspection

Nor-Cal Products, Inc. 1967 South Oregon St. Yreka, CA 96097 USA

Tel: 800-824-4166 or 530-842-4457 www.n-c.com

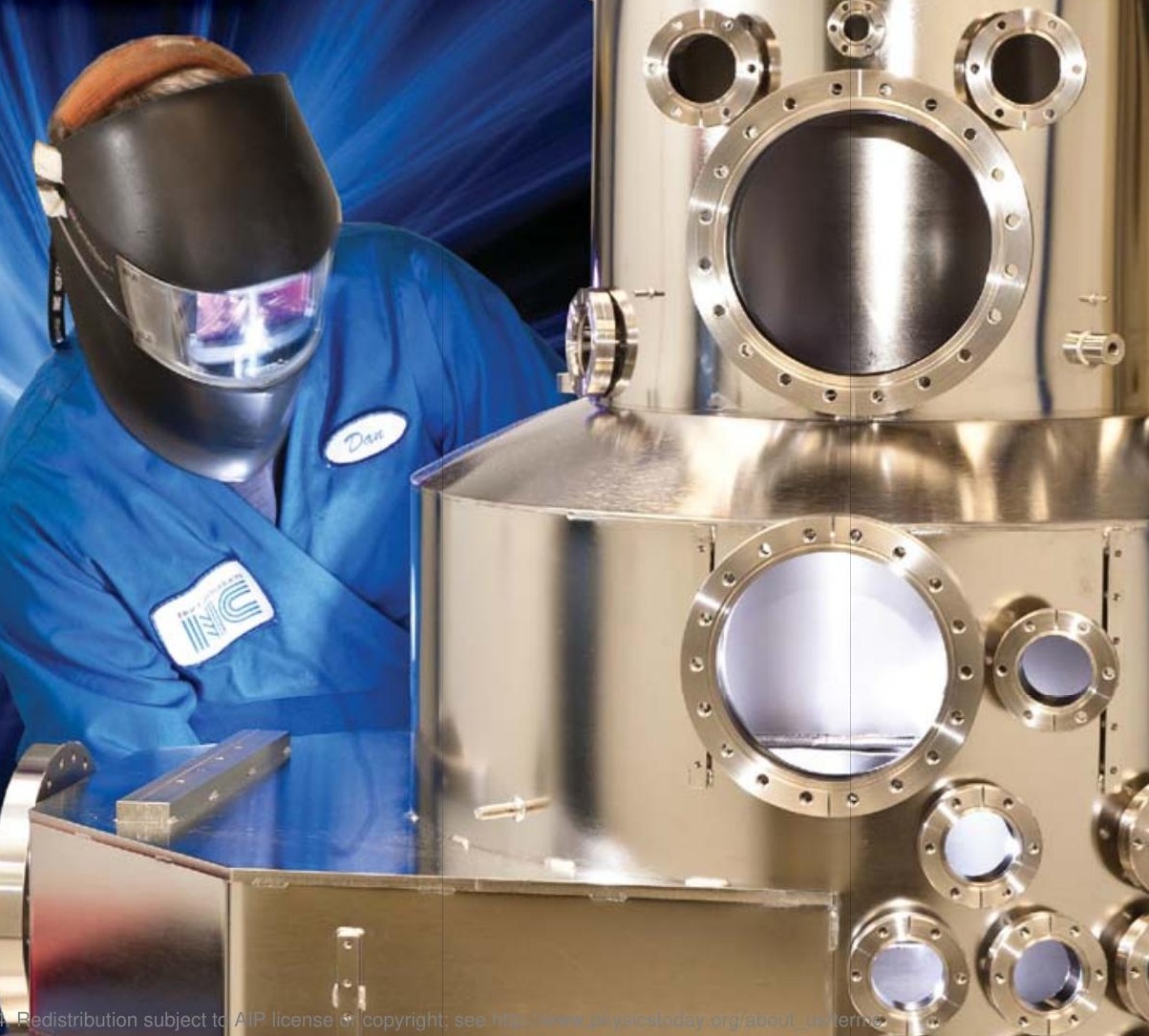


may be the subject of a book by future historians, who would do well to be as lucid in their analysis as Gavroglu and Simões have been.

Alán Aspuru-Guzik Harvard University Cambridge, Massachusetts

\section{new books}

\section{acoustics}

Digital Sonar Design in Underwater Acoustics: Principles and Applications. Q. Li. Advanced Topics in Science and Technology in China. Zhejiang U. Press, Hangzhou, China, and Springer, Berlin, 2012. $\$ 269.00$ (641 pp.). ISBN 978-3-642-18289-1

\section{astronomy and astrophysics}

XV Special Courses at the National Observatory of Rio de Janeiro. E. Telles, R. Dupke, D. Lazzaro, eds. AIP Conference Proceedings 1386. Proc. course, Rio de Janeiro, Brazil, Oct. 2010. AIP, Melville, NY, 2011. \$135.00 (171 pp.). ISBN 978-07354-0950-7

Astrophysics of Neutron Stars 2010: A Conference in Honor of M. Ali Alpar. E. Göğüş, T. Belloni, Ü. Ertan, eds. AIP Conference Proceedings 1379. Proc. conf., Çeşme, Turkey, Aug. 2010. AIP, Melville, NY, 2011. \$144.00 (231 pp.). ISBN 978-07354-0939-2

The Chemical Cosmos: A Guided Tour. S. Miller. Astronomers' Universe. Springer, New York, 2012. \$29.95 paper (236 pp.). ISBN 978-1-4419-8443-2

Dark Nebulae, Dark Lanes, and Dust Belts. A. Cooke. Patrick Moore's Practical Astronomy Series. Springer, New York, 2012. \$39.95 paper (243 pp.). ISBN 978-14614-1185-7

Treasures of the Southern Sky. R. Gendler, L. L. Christensen, D. Malin. Springer, New York, 2011. \$39.95 (219 pp.). ISBN 978-14614-0627-3

\section{biological and medical physics}

Control of Cell Fate in the Circulatory and Ventilatory Systems. M. Thiriet. Biomathematical and Biochemical Modeling of the Circulatory and Ventilatory Systems 2. Springer, New York, 2012. \$199.00 (536 pp.). ISBN 978-1-4614-0328-9

Nanotechnology for Biology and Medicine: At the Building Block Level. G. A. Silva, V. Parpura, eds. Fundamental Biomedical Technologies. Springer, New York, 2012. \$189.00 (234 pp.). ISBN 978-0-38731282-8

Single-Molecule Biophysics: Experiment and Theory. T. Komatsuzaki et al., eds. Advances in Chemical Physics 146. Wiley, Hoboken, NJ, 2012. \$130.00 (494 pp.). ISBN 978-1-118-05780-3

\section{chemical physics}

Chemical Engineering: An Introduction. M. M. Denn. Cambridge Series in Chemical Engineering. Cambridge U. Press, New York, 2012. \$125.00, $\$ 48.00$ paper (265 pp.). ISBN 978-1-107-01189-2, ISBN 978-1-10766937-6 paper

Multiscale Molecular Methods in Applied Chemistry. B. Kirchner, J. Vrabec, eds. Topics in Current Chemistry 307. Springer, Berlin, 2012. \$349.00 (326 pp.). ISBN 978-3-642-24967-9

Neural Networks in Chemical Reaction Dynamics. L. M. Raff, R. Komanduri, M. Hagan, S. T. S. Bukkapatnam. Oxford U. Press, New York, 2012. \$79.95 (283 pp.). ISBN 978-0-19-976565-2

Phase Interaction in the Metal-Oxide Melts-Gas System: The Modeling of Structure, Properties and Processes. V. Boronenkov et al. Engineering Materials. Springer, Berlin, 2012. \$179.00 (407 pp.). ISBN 978-3-642-22376-1

\section{computers and computational physics}

Companion to the Papers of Donald Knuth. D. E. Knuth. CSLI Lecture Notes Number 202. Center for the Study of Language and Information, Stanford, CA, 2011. \$70.00, $\$ 35.00$ paper (441 pp.). ISBN 978-1-57586-635-2, ISBN 978-1-57586-6345 paper

\section{cosmology and relativity}

Matter, Dark Matter, and Anti-Matter: In Search of the Hidden Universe. A. Mazure, V. Le Brun (translated from French by B. Mizon). Springer-Praxis Books in Popular Astronomy. Praxis/Springer, New York, 2012. \$34.95 paper (172 pp.). ISBN 978-1-4419-8821-8

A New Perspective on Relativity: An Odyssey in Non-Euclidean Geometries. B. H. Lavenda. World Scientific, Hackensack, NJ, 2012. \$187.00 (668 pp.). ISBN 978981-4340-48-9

\section{device physics}

Chips 2020: A Guide to the Future of Nanoelectronics. B. Hoefflinger, ed. Frontiers Collection. Springer, Berlin, 2012. \$109.00 (477 pp.). ISBN 978-3-64222399-0

\section{instrumentation and techniques}

Translational Dynamics and Magnetic Resonance: Principles of Pulsed Gradient Spin Echo NMR. P. T. Callaghan. Oxford U. Press, New York, 2011. \$94.95 (547 pp.). ISBN 978-0-19-955698-4

\section{materials science}

Heterogeneous Ferroelectric Solid Solutions: Phases and Domain States. V. Y. Topolov. Springer Series in Materials Science
151. Springer, Berlin, 2012. $\$ 129.00$ (156 pp.). ISBN 978-3-642-22482-9

Liquid Crystal Displays: Fundamental Physics and Technology. R. H. Chen. Series in Display Technology. Wiley, Hoboken, NJ, 2011. \$95.00 (497 pp.). ISBN 9780-470-93087-8

\section{nonlinear science and chaos}

Chaotic Flows: Correlation Effects, Transport, and Structures. O. G. Bakunin. Springer Series in Synergetics. Springer, Berlin, 2011. \$99.00 (351 pp.). ISBN 978-3642-20349-7

Dynamical Systems and Methods. A. C. J. Luo, J. A. T. Machado, D. Baleanu, eds. Springer, New York, 2012. \$179.00 (348 pp.). ISBN 978-1-4614-0453-8

Nonlinear Filtering and Optimal Phase Tracking. Z. Schuss. Applied Mathematical Sciences 180. Springer, New York, 2012. \$74.95 (262 pp.). ISBN 978-1-4614-0486-6

Nonlinear Internal Waves in Lakes. K. Hutter, ed. Advances in Geophysical and Environmental Mechanics and Mathematics. Springer, Berlin, 2012. \$179.00 (277 pp.). ISBN 978-3-642-23437-8

\section{nuclear physics}

Annual Review of Nuclear and Particle Science. Vol. 61. B. R. Holstein, W. C. Haxton, A. Jawahery, eds. Annual Reviews, Palo Alto, CA, 2011. \$86.00 (532 pp.). ISBN 978-0-8243-1561-0

Nuclear Physics with Polarized Particles. H. Paetz gen. Schieck. Lecture Notes in Physics 842. Springer, Berlin, 2012. \$59.95 paper (182 pp.). ISBN 978-3-642-24225-0

\section{optics and photonics}

Industrial Applications of Laser Diagnostics. Y. Deguchi. CRC Press/Taylor \& Francis, Boca Raton, FL, 2012. \$139.95 (280 pp.). ISBN 978-1-4398-5337-5

Integrated Modeling of Telescopes. T. Andersen, A. Enmark. Astrophysics and Space Science Library 377. Springer, New York, 2011. \$199.00 (545 pp.). ISBN 978-14614-0148-3

Optical Properties of Nanostructured Metallic Systems: Studied with the FiniteDifference Time-Domain Method. S. G. Rodrigo. Springer Theses. Springer, Berlin, 2012. \$129.00 (163 pp.). ISBN 978-3-64223084-4

The Optics of Life: A Biologist's Guide to Light in Nature. S. Johnsen. Princeton U. Press, Princeton, NJ, 2012. \$99.50 (336 pp.). ISBN 978-0-691-13990-6

Photographic Science: Advances in Nanoparticles, J-Aggregates, Dye Sensitization, and Organic Devices. T. Tani. Oxford U. Press, New York, 2011. $\$ 98.50$ (290 pp.). ISBN 978-0-19-957295-3 